\title{
Covalent modification of a ten-residue cationic antimicrobial peptide with levofloxacin
}

\author{
Carlos A. Rodriguez, Emilios A. Papanastasiou, Melanie Juba and Barney Bishop*
}

Department of Chemistry and Biochemistry, George Mason University, Fairfax, VA, USA

\section{Edited by:}

Carissa M. Soto, Naval Research

Laboratory, USA

Reviewed by:

Paola Laurienzo, Italian Research Council (CNR), Italy

Huiwang Ai, University of California,

Riverside, USA

*Correspondence:

Barney Bishop, Department of

Chemistry and Biochemistry.

George Mason University,

4400 University Drive, 3E2, Fairfax,

VA 22030, USA

e-mail: bbishop1@gmu.edu
The rampant spread of antibiotic resistant bacteria has spurred interest in alternative strategies for developing next-generation antibacterial therapies. As such, there has been growing interest in cationic antimicrobial peptides (CAMPs) and their therapeutic applications. Modification of CAMPs via conjugation to auxiliary compounds, including small molecule drugs, is a new approach to developing effective, broad-spectrum antibacterial agents with novel physicochemical properties and versatile antibacterial mechanisms. Here, we've explored design parameters for engineering CAMPs conjugated to small molecules with favorable physicochemical and antibacterial properties by covalently affixing a fluoroquinolone antibiotic, levofloxacin, to the ten-residue CAMP Pep-4. Relative to the unmodified Pep-4, the conjugate was found to demonstrate substantially increased antibacterial potency under high salt concentrations. Historically, it has been observed that most CAMPs lose antibacterial effectiveness in such high ionic strength environments, a fact that has presented a challenge to their development as therapeutics. Physicochemical studies revealed that P4LC was more hydrophobic than Pep-4, while mechanistic findings indicated that the conjugate was more effective at disrupting bacterial membrane integrity. Although the inherent antibacterial effect of the incorporated levofloxacin molecules did not appear to be substantially realized in this conjugate, these findings nevertheless suggest that covalent attachment of small molecule antibiotics with favorable physicochemical properties to CAMPs could be a promising strategy for enhancing peptide performance and overall therapeutic potential. These results have broader applicability to the development of future CAMP-antibiotic conjugates for potential therapeutic applications.

Keywords: cationic antimicrobial peptide, peptide conjugate, antibiotics, peptide modification, levofloxacin

\section{INTRODUCTION}

The emergence and spread of bacterial resistance to conventional antibiotics has resulted in interest in cationic antimicrobial peptides (CAMPs) as a potential therapeutic alternative (Gordon et al., 2005; Seo et al., 2012). These peptides demonstrate broadspectrum antimicrobial activity and are essential elements of innate immunity in higher organisms. Yet, despite their extensive use in nature, bacteria have failed to develop wide-spread resistance to CAMPs, which has not been the case for conventional antibiotics (Zasloff, 2002). While CAMPs demonstrate extensive sequence and structural diversity, they are generally rich in cationic amino acids and adopt amphipathic structures that result in spatial partitioning of basic and hydrophobic residues. These peptides are thought to exert their antibacterial effect via mechanisms that at some level involve the targeting of anionic bacterial membranes through non-specific electrostatic and hydrophobic interactions. Many CAMPs are thought to also bind bacterial receptors and enzymes, or otherwise interfere with essential cellular processes (Epand and Vogel, 1999; Brogden, 2005; Jenssen et al., 2006).

While CAMPs represent a promising class of prospective therapeutics, their development as viable treatments has proven challenging, with one major factor being that the effectiveness of many CAMPs are diminished or even abolished under salt concentrations consistent with physiologically relevant environments (Park et al., 2004; Yu et al., 2011; Chu et al., 2013). Researchers have investigated various strategies, including conjugation to auxiliary compounds, in order to enhance CAMP antibacterial performance and potential therapeutic utility (Arnusch et al., 2012; Devocelle, 2012). Conjugation is an appealing strategy because it provides a means for introducing new functionalities and directly enhancing CAMP antibacterial activity. For example, CAMPs have been conjugated to fatty acids (Li et al., 2013), sugars (Pal et al., 2011), pheromones, antibodies, synthetic polymers, and small molecule drugs to yield peptide constructs with improved antibacterial activity relative to their respective unmodified parent peptide variants (Devocelle, 2012). However, while conjugation can improve the performance of CAMPs, it has also been shown in some instances to abrogate antibacterial effectiveness (Chu-Kung et al., 2004; Radzishevsky et al., 2005). Therefore, the effect that conjugation may have on CAMP structure and physicochemical properties (e.g., charge, hydropathy, and sterics, etc.) must be considered when engineering constructs. Conjugation of CAMPs to small molecules with favorable physicochemical 
properties (such as hydrophobic and/or cationic functionalities) would provide a highly controlled means for augmenting peptide antibacterial performance. The incorporation of small molecule antibiotics in CAMP-based conjugates presents a particularly intriguing strategy, as these compounds could influence peptide effectiveness not only via alteration of physicochemical properties, but also through their intrinsic antibacterial activities. In this regard, fluoroquinolone antibiotics, which present both hydrophobic (e.g., aromatic and aliphatic moieties) and cationic functionalities, represent attractive candidates. Additionally, from a synthetic perspective, the carboxylate moieities that fluoroquinolones contain lend themselves to ready conjugation with CAMP primary amino groups.

In our previous studies, we found that Pep-4, a highly cationic peptide with a sequence (RGRRSSRRKK-NH $\mathrm{N}_{2}$ ) based on the C-terminal portion of human beta defensin-3 (hBD-3), retained significant antibacterial activity following acetylation of its N-terminal and side chain amino groups, despite the associated reduction in charge from +8 to +5 (Papanastasiou et al., 2009). These results suggest that this peptide is amenable to chemical modification and may be a good candidate for incorporation in CAMP-conjugates. Additionally, the sequence of Pep-4 provides a limited number of reactive functionalities, allowing convenient chemical modification with small molecules while reducing the potential for deleterious side reactions and byproducts. These qualities also facilitate isolation and characterization. Moreover, the small size of Pep-4 makes it especially appealing for use in CAMP-conjugates, as it lends itself to cost effective synthesis (Seo et al., 2012).

In order to explore design parameters for engineering antibacterial CAMP-conjugates and the incorporation of small molecules, such as antibiotics, we have synthesized a CAMPconjugate consisting of a fluoroquinolone, levofloxacin (LVFX), covalently attached to the scaffold peptide Pep-4 via the primary amino groups present in the peptide. These studies have focused on evaluating the antibacterial performance of the Pep-4-LVFX Conjugate, P4LC, against the model gram-negative bacterium E. coli and gram-positive bacterium $B$. cereus. Our studies reveal that incorporation of LVFX significantly enhances the effectiveness of the conjugate under physiologically relevant environmental salt concentrations relative to the unmodified scaffold peptide Pep-4. These findings suggest that conjugation of CAMPs to auxiliary compounds, such as small molecule antibiotics with favorable physicochemical properties, to generate hybrid constructs could be a promising strategy for enhancing peptide therapeutic potential.

\section{MATERIALS AND METHODS}

Levofloxacin (LVFX), N-methylmorpholine (NMM) and resazurin were purchased from Sigma-Aldrich, Co. LLC (St. Louis, MO, USA). Bicinchoninic acid (BCA) and SYTOX Green were purchased from ThermoFisher Scientific, Inc. (Waltham,

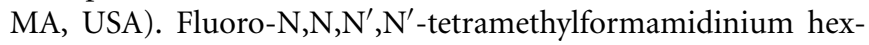
afluorophosphate (TFFH) was purchased from EMD Millipore (a division of Merck KGaA; Darmstadt, Germany), Fmoc-Gly-Wang resin from Peptides International, Inc. (Louisville, KY, USA), and DiSC(3)5 from Anaspec, Inc. (Fremont, CA, USA). Deionized water $\left(\mathrm{dH}_{2} \mathrm{O}\right)$ was prepared using a Milli-Q Synthesis A10 system (Millipore). The bacterial strains E. coli (\#25922) and B. cereus (\#11778) were purchased from American Type Culture Collection (ATCC, Manassas, VA, USA). Pep-4 ( $\geq 95 \%$ purity) was custom synthesized by Genscript USA, Inc. (Piscataway, NJ, USA). Melittin ( $\geq 95 \%)$ was purchased from Anaspec, Inc., and indolicidin was synthesized ( $\geq 95 \%$ purity) by AAPPTec, LLC (Louisville, KY, USA). Peptide identities were verified via matrix assisted laser desorption ionization time-of-flight (MALDI-TOF) mass spectrometry using a Shimadzu AXIMA Performance. Additionally, Pep-4 and the conjugate were submitted for amino acid analysis (UC Davis Genome Center Proteomics Core Facility) in order to establish molar concentrations.

\section{P4LC SYNTHESIS AND PURIFICATION}

The carboxyl group of LVFX allowed for conjugation to Pep-4 via direct acylation of the peptide's N-terminal and lysine side chain amino groups. LVFX was preactivated by converting its carboxyl moiety into an acyl fluoride in order to facilitate nucleophilic attack by peptide amino groups. Equimolar amounts of LVFX $(6.7 \mathrm{mg}, 18.6 \mathrm{mmol})$ and TFFH $(4.90 \mathrm{mg}, 18.6 \mathrm{mmol})$ were dissolved in $500 \mu \mathrm{L}$ of anhydrous DMF, and $20 \mu \mathrm{L}$ of NMM was then added to the solution. This reaction was allowed to stir at room temperature ( $\mathrm{rt}$ ), under $\mathrm{N}_{2}$ in the dark. After $1 \mathrm{~h}$, Pep$4(2.4 \mathrm{mg}, 1.86 \mathrm{mmol})$ dissolved in $200 \mu \mathrm{L}$ of anhydrous DMF was added to the reaction and allowed to continue stirring at $\mathrm{rt}$, under $\mathrm{N}_{2}$ in the dark. While the coupling reaction was stirring, Fmoc-Glycine-Wang resin (200 mg, $0.63 \mathrm{mmol} / \mathrm{g}$ amine loading) was suspended in $8 \mathrm{~mL}$ of DMF with agitation for $30 \mathrm{~min}$ to swell the resin, and the solvent was then removed via vacuum filtration. The suspension and filtration process was repeated. The swelled resin was then suspended in $8 \mathrm{~mL}$ of $50 \%$ piperidine in DMF for $30 \mathrm{~min}$ in order to remove the Fmoc protecting group. The reaction mixture was vacuum filtered and the resin resuspended in $8 \mathrm{~mL}$ of DMF and agitated for $15 \mathrm{~min}$. The resin suspension was then vacuum filtered, and the deprotected particles were transferred to the reaction vessel. Following addition of the resin, the reaction was left stirring in the dark under $\mathrm{N}_{2}$, overnight. Thereafter, the contents of the reaction vessel were filtered through a course frit directly into cold diethyl ether, and the resulting suspension was centrifuged so as to pellet the precipitated material. The pelleted precipitate was then dried under vacuum in order to remove residual ether. Crude conjugate was subsequently dissolved in $10 \mathrm{~mL}$ of $10 \mathrm{mM} \mathrm{NaCl}$ and dialyzed (0.5-1 kD M $\mathrm{w}_{\mathrm{w}}$ cutoff) in $10 \mathrm{~mL} 10 \mathrm{mM} \mathrm{NaCl}$ against $2 \mathrm{~L} \mathrm{dH}_{2} \mathrm{O}$, which was replaced every $8 \mathrm{~h}(3 \mathrm{x})$. The dialyzed solution was then lyophilized to yield $3.1 \mathrm{mg}$ of purified P4LC ( $~ 87 \%$ yield).

\section{MASS SPECTROMETRY}

Samples dissolved in $\mathrm{dH}_{2} \mathrm{O}(1 \mathrm{pmol} / \mu \mathrm{L})$ were mixed with $\alpha$-cyano-4-hydroxycinnamic acid (CHCA) matrix solution $(10 \mathrm{mg} / \mathrm{ml}$ in $50: 50$ water/acetonitrile with $0.1 \%$ TFA) and deposited onto a stainless steel target plate (Shimadzu Kratos Analytical) in $1 \mu \mathrm{L}$ aliquots. Mass spectra were collected using a Shimadzu AXIMA Performance MALDI-TOF mass spectrometer equipped with a $337 \mathrm{~nm} \mathrm{~N}$ laser in reflectron mode and represent the average of at least 50 accumulated profiles. The 
laser repetition rate was set to $50 \mathrm{~Hz}$, and laser power was set to between 50 and $70 \%$. The instrument was externally calibrated using angiotensin II, angiotensin I, and Adrenocorticotropin hormone (fragment 18-39). Lower molecular weight regions of spectra were assessed with the ion gate turned off, and control spectra were generated for matrix alone. CHCA peaks were used for internal calibration of the lower molecular weight regions of sample spectra. Matrix m/z values were verified using MassBank Mass Spectral Database (Accession: MCH00005).

\section{ANTIBACTERIAL PERFORMANCE ASSAYS}

The antibacterial activities of P4LC, Pep-4, LVFX, and free Pep-4 in combination with free LVFX (Pep-4/LVFX) were determined in a microplate-based assay using resazurin as an indicator for cell viability. Metabolically active cells convert resazurin, which is not fluorescent, to the highly fluorescent resorufin $\left(530 / 590 \mathrm{~nm}_{\mathrm{em}}\right)$, and the rate of this conversion provides a means for quantifying the concentration of viable bacteria (Shiloh et al., 1997; Lemos and Carareto-Alves, 1998; Okuda et al., 2006; Mariscal et al., 2009). In order to assess the effect environmental ionic strength had on antibacterial effectiveness, assays were conducted in buffers with the following ionic strengths: $26 \mathrm{mM}, 111 \mathrm{mM}$, and $167 \mathrm{mM}$.

Frozen enumerated aliquots of bacteria were thawed and diluted into sterile buffer to a bacterial concentration of $2 \times$ $10^{6} \mathrm{CFU} / \mathrm{mL}$. Wells of a 96-well polypropylene microtiter plate (Greiner Bio-One) were charged with $50 \mu \mathrm{L}$ aliquots of buffer solutions containing serially diluted peptide, conjugate, or drug followed by $50 \mu \mathrm{L}$ aliquots of diluted bacterial cells. Assays for each compound were prepared in triplicate. Control wells were prepared where the peptide/conjugate/drug solution was replaced with an equal volume of buffer alone. Following addition of bacteria, the microtiter plates were incubated for $3 \mathrm{~h}$ at either $37^{\circ} \mathrm{C}$ (E. coli) or $30^{\circ} \mathrm{C}$ (B. cereus). Aliquots of PBS solution $(100 \mu \mathrm{L})$ containing resazurin and $\mathrm{MHB}$ were then added to each well to afford final concentrations of $100 \mu \mathrm{M}$ resazurin and $0.2 \%$ $\mathrm{MHB}$ (wt/vol) for E. coli and $12.5 \mu \mathrm{M}$ resazurin and $0.05 \% \mathrm{MHB}$ (wt/vol) for B. cereus. Plates were then immediately placed in a SpectraMax Gemini EM plate-reading fluorometer for overnight monitoring of fluorescence $\left(530 \mathrm{~nm}_{\mathrm{ex}} / 590 \mathrm{~nm}_{\mathrm{em}}\right)$ at either $37^{\circ} \mathrm{C}$ (E. coli) or $30^{\circ} \mathrm{C}$ (B. cereus) with intermittent shaking. Onset time of half maximal fluorescence $\left(\mathrm{T}_{0.5}\right)$ observed for each well was computed using the microplate data analysis software. In order to determine bacterial survival, it was necessary to establish correlations between bacterial concentration $(\mathrm{CFU} / \mathrm{mL})$ and $\mathrm{T}_{0.5}$ values. Therefore, standard curve equations were generated in preliminary experiments using bacterial suspensions serially diluted $\left(\sim 10^{6} \mathrm{CFU} / \mathrm{mL}-10^{3} \mathrm{CFU} / \mathrm{mL}\right)$ in each of the three buffers used in the antibacterial assays. Plotting initial bacterial concentrations (determined via dilution plating onto MHB Agar plates) against observed $\mathrm{T}_{0.5}$ values afforded equations 1 (E. coli) and 2 (B. cereus), which were used to interpolate viable bacterial concentration $(\mathrm{CFU} / \mathrm{mL})$ following incubation with peptide, conjugate or drug. The $\mathrm{Y}$-intercept $\left(\mathrm{Y}_{\text {int }}\right)$ values for equations generated for the varied ionic strength buffer conditions were 9.41 (26 mM), $9.19(111 \mathrm{mM})$, and $9.24(167 \mathrm{mM})$ for E. coli, and 5.91 (26 mM), $6.20(111 \mathrm{mM})$, and $6.36(167 \mathrm{mM})$ for B. cereus.

$$
\begin{aligned}
\log \left(\mathrm{CFU} / \mathrm{mL}_{\text {E.coli }}\right) & =-2.00 \times 10^{-4}\left(\mathrm{~T}_{0.5}\right)+\mathrm{Y}_{\mathrm{int}} \\
\log \left(\mathrm{CFU} / \mathrm{mL}_{\text {B.cereus }}\right) & =-1.00 \times 10^{-4}\left(\mathrm{~T}_{0.5}\right)+\mathrm{Y}_{\mathrm{int}}
\end{aligned}
$$

Antibacterial effectiveness against each microbe was determined by plotting bacterial survival as a function of the log of the concentration of P4LC, Pep-4, LVFX, or Pep-4/LVFX, and fitting the resulting data to a variable-slope sigmoidal regression model (equation 3) using Graphpad Prism 5 (GraphPad Software, Inc.). In this equation, $\log \left(\mathrm{EC}_{50}\right)$ represents the $\log$ of the concentration of P4LC, Pep-4, LVFX, or Pep-4/LVFX required to kill half of the bacterial population, where $S_{\min }$ and $S_{\max }$ correspond to the minimal and maximal bacterial survival values (respectively), and HS is the parameter defining the steepness of the transition slopes of sigmoidal survival curves.

$$
\begin{aligned}
\text { Bacterial Survival }= & \mathrm{S}_{\min }+\left(\mathrm{S}_{\max }-\mathrm{S}_{\min }\right) / \\
& \left(1+10^{\log (\mathrm{EC} 50)-\log (\mathrm{PC}) * \mathrm{HS}}\right)
\end{aligned}
$$

Best-fit $\log \left(\mathrm{EC}_{50}\right)$ values generated for each compound were used to compare the antibacterial effectiveness of P4LC, Pep-4, LVFX, and Pep-4/LVFX against each bacterium. Antilogs of the

\begin{tabular}{|c|c|c|c|c|}
\hline & P4LC & Pep-4 & Pep-4/LVFX & LVFX \\
\hline \multicolumn{5}{|c|}{ E. COLI } \\
\hline$\mu_{1}$ & $0.0167(0.0132-0.0230)$ & $0.0168(0.0123-0.0234)$ & $0.00375(0.00314-0.00447)$ & $0.00281(0.00228-0.00344)$ \\
\hline$\mu_{2}$ & $1.71(1.60-1.81)$ & $28.3(17.2-46.7)$ & $0.00487(0.00387-0.00617)$ & $0.00223(0.00164-0.00303)$ \\
\hline$\mu_{3}$ & $1.51(1.41-1.82)$ & $29.4^{*}(21.9-35.4)^{*}$ & $0.00404(0.00294-0.00556)$ & $0.00277(0.00200-0.00385)$ \\
\hline \multicolumn{5}{|c|}{ B. CEREUS } \\
\hline$\mu_{1}$ & $0.0218(0.0156-0.0287)$ & $0.0271(0.0217-0.0343)$ & $0.112(0.0794-0.165)$ & $0.212(0.104-0.450)$ \\
\hline$\mu_{2}$ & $2.17(2.01-2.25)$ & $178 *(142-223) *$ & $0.941(0.645-1.27)$ & $0.591(0.381-0.918)$ \\
\hline$\mu_{3}$ & $40.0(27.3-72.0)$ & $404^{*}(155-462)^{*}$ & $1.37(0.801-2.32)$ & $0.981(0.57-1.67)$ \\
\hline
\end{tabular}
$\log \left(\mathrm{EC}_{50}\right)$ values, the $\mathrm{EC}_{50}$ values, are tabulated in Table $\mathbf{1}$ along with their respective $95 \%$ confidence intervals.

Table 1 | Antibacterial effectiveness.

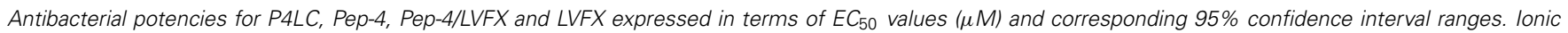
strengths of assay media correspond to: $\mu_{1}=26 \mathrm{mM}, \mu_{2}=111 \mathrm{mM}$, and $\mu_{3}=167 \mathrm{mM}$.

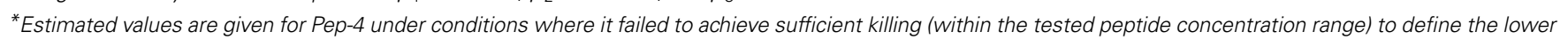
survival boundary for fitting to Equation 3. 


\section{DiSC (3)5 MEMBRANE DEPOLARIZATION ASSAY}

Enumerated frozen aliquots of $E$. coli and B. cereus cells were thawed and washed $3 \mathrm{x}$ with buffer $\left(10 \mathrm{mM} \mathrm{NaPO}_{4}, \mathrm{pH} 7.4\right)$. The washed cells were diluted in $10 \mathrm{mM} \mathrm{NaPO}_{4}$ buffer containing $10 \mathrm{ug} / \mathrm{mL} \operatorname{DiSC}(3) 5$ to afford a concentration of $4 \times$ $10^{7} \mathrm{CFU} / \mathrm{mL}$. Bacterial suspension was added to the wells of a black polypropylene microtiter plate (Greiner Bio-One) in $100 \mu \mathrm{L}$ aliquots, and fluorescence was monitored (rt, with lid on) using a SpectraMax Gemini EM plate-reading fluorometer $\left(622 \mathrm{~nm}_{\mathrm{ex}} / 670 \mathrm{~nm}_{\mathrm{em}}\right)$ until fluorescence quenching stabilized and maximal DiSC(3)5 uptake was achieved. Aliquots $(100 \mu \mathrm{L})$ of P4LC, Pep-4, LVFX, or Pep-4/LVFX were added to the bacteria and changes in fluorescence were monitored for $30 \mathrm{~min}$ with the lid off. The final concentrations of each assessed compound in the wells were $33 \mu \mathrm{M}$ (P4LC and Pep-4), $126 \mu \mathrm{M}$ (Pep-4/LVFX), and $93 \mu \mathrm{M}$ (LVFX), while final bacterial concentrations were $2 \times 10^{7} \mathrm{CFU} / \mathrm{mL}$. Assays were performed in triplicate for each compound assessed. Depolarization assays based on DiSC(3)5 are extremely time-sensitive; therefore, triplicate sets for each compound were prepared simultaneously using a multichannel pipettor. Prior experiments verified that each tested compound was able to exert full killing under the assay conditions. A negative control containing only bacteria and DiSC(3) 5 was used to establish background fluorescence, while maximal membrane depolarization was established using melittin $(33 \mu \mathrm{M})$, a known pore-forming CAMP (Lee et al., 2013 b); these controls provided references for establishing relative effectiveness of P4LC, Pep-4, LVFX, and Pep-4/LVFX. The fluorescence kinetics data sets were normalized by setting emitted fluorescence to 0 at $t=0 \mathrm{~s}$ and presenting fluorescence intensity values as a fraction of maximal fluorescence observed for melittin.

\section{SYTOX GREEN MEMBRANE PERTURBATION ASSAY}

Enumerated frozen aliquots of $E$. coli and B. cereus cells were thawed and washed $3 \mathrm{x}$ with buffer $\left(10 \mathrm{mM} \mathrm{NaPO}_{4}, \mathrm{pH} 7.4\right)$. The washed cells were diluted to a concentration of $4 \times 10^{7}$ $\mathrm{CFU} / \mathrm{mL}$ in $10 \mathrm{mM} \mathrm{NaPO}_{4}(\mathrm{pH} 7.4)$ buffer containing $5 \mu \mathrm{M}$ SYTOX Green, and the resulting suspension then stored in the dark for $\sim 20 \mathrm{~min}$. The bacterial suspension was then distributed in $100 \mu \mathrm{L}$ aliquots to wells of a black polypropylene microtiter plate (Greiner Bio-One). Aliquots $(100 \mu \mathrm{L})$ of buffer containing P4LC, Pep-4, LVFX, or Pep-4/LVFX were then added to wells containing cell suspension and gently mixed. The fluorescence of each well was immediately monitored (without the lid) using a SpectraMax Gemini EM plate-reading fluorometer $\left(485 / 520 \mathrm{~nm}_{\mathrm{em}}\right)$. As SYTOX Green assays can be timesensitive, assays were prepared in triplicate using a multichannel pipettor. The reported SYTOX Green data reflects observations from biological triplicates. Antibacterial assays confirmed that each compound was able to exert full killing under these conditions and at the concentrations used in the DiSC(3) 5 assay $(33 \mu \mathrm{M}$ P4LC, $33 \mu \mathrm{M}$ Pep-4, $126 \mu \mathrm{M}$ Pep-4/LVFX, and $93 \mu \mathrm{M}$ LVFX). A negative control containing only bacteria and SYTOX Green was used to determine background fluorescence, and maximal perturbation of the bacterial cell membranes was established using melittin. The fluorescence kinetics data sets were normalized by setting emitted fluorescence to 0 at $t=0 \mathrm{~s}$ and presenting fluorescence intensity values as a fraction of maximal fluorescence observed for melittin.

\section{STATISTICAL ANALYSIS}

An $\mathrm{F}$ test was used for determining whether $\log \left(\mathrm{EC}_{50}\right)$ values generated for the assessed compounds were significantly different from each other (computed using GraphPad Prism). For membrane depolarization and perturbation experiments, fluorescence data was analyzed by comparing best-fit curves (GraphPad Prism). Fluorescence kinetic curves were fit to a polynomial regression model (equation 4) to allow for statistical comparison of the fluorescence data via an F test, with all four best-fit parameters used as criteria.

$$
\mathrm{RFU}=\mathrm{A}_{0}+\mathrm{A}_{1}(\mathrm{t})+\mathrm{A}_{2}(\mathrm{t})^{2}+\mathrm{A}_{3}(\mathrm{t})^{3}+\mathrm{A}_{4}(\mathrm{t})^{4}
$$

\section{DISTRIBUTION COEFFICIENT}

The relative hydrophobicities of P4LC, Pep-4, and LVFX were established using a biphasic system consisting of immiscible 1octanol and $10 \mathrm{mM} \mathrm{NaPO}_{4}(\mathrm{pH}$ 7.4) to determine their respective distribution coefficients $\left(\mathrm{D}_{7.4}\right)$, with $\mathrm{D}_{7.4}$ corresponding to the concentration ratio of each compound between the octanol and aqueous phases (Brillault et al., 2010; Cheng et al., 2012; Chyan et al., 2014). In these experiments, P4LC, Pep-4 or free LVFX dissolved in $100 \mu \mathrm{L}$ of $10 \mathrm{mM} \mathrm{NaPO}_{4}$ (pH 7.4) buffer was combined with $100 \mu \mathrm{L}$ of 1 -Octanol in a $1.5 \mathrm{~mL}$ low binding polypropylene microcentrifuge tube (Corning). Each tube was vortexed for $10 \mathrm{~min}$ and the contained solvent allowed to settle. Once the aqueous and octanol layers had reestablished and fully separated, $25 \mu \mathrm{L}$ aliquots were removed from the aqueous phase using a micropipette, and the peptide or conjugate concentration determined using an absorbance-based BCA kit (Wrolstad et al., 2004). Aqueous phase Pep-4 and P4LC concentrations were determined via interpolation based on standard curves that had been generated using two-fold serially diluted peptide or conjugate dissolved in $10 \mathrm{mM} \mathrm{NaPO}_{4}(\mathrm{pH}$ 7.4). The maximal concentrations of Pep- 4 and P4LC in the calibration curves were also established using amino acid analysis (UC Davis Genome Center Proteomics Core Facility). The results from amino acid analysis were in agreement with those obtained using the BCA kit. The concentration of LVFX in the aqueous layer was interpolated from calibration curves established using absorbance at $298 \mathrm{~nm}$ (LVFX absorbs strongly at this wavelength). Indolicidin and melittin were used as reference peptides in these studies. The sequence of indolicidin suggests that it is highly hydrophobic, while that of melittin indicates that it should be moderately hydrophobic. Computational verification of the hydrophobicity of these reference peptides was performed using the Hopp and Woods scale (Hopp and Woods, 1981). The $\mathrm{D}_{7.4}$ values generated for P4LC, Pep-4, LVFX, indolicidin, and melittin were calculated (equation 5) based on their respective concentrations in the aqueous phase ([peptide $]_{\text {PO4buffer }}$ ) of the water/octanol biphasic system and their concentrations in the initial stock solution ([peptide $\left.]_{\text {total }}\right)$. Values 
are averaged from six replicates.

$$
\begin{aligned}
\log D_{7.4} & =\log \left(\begin{array}{l}
\left([\text { peptide }]_{\text {total }}-[\text { peptide }]_{\text {PO4buffer }}\right) / \\
\left([\text { peptide }]_{\text {PO4buffer }}\right)
\end{array}\right) \\
& =\log \left([\text { peptide }]_{\text {octanol }} /[\text { peptide }]_{\text {PO4buffer }}\right)
\end{aligned}
$$

\section{RESULTS}

\section{SYNTHESIS AND PURIFICATION OF Pep-4-LVFX CONJUGATE}

The carboxyl moiety of LVFX allowed for conjugation to Pep-4 via direct acylation of N-terminal and lysine side chain amino groups on the peptide (Figure 1). LVFX was preactivated with TFFH to convert the carboxyl moiety to an acyl fluoride prior to introduction of Pep-4. Excess activated LVFX was captured using a glycineWang resin. The resulting particle suspension was filtered through a medium glass frit into cold ether in order to remove the resin and precipitate the desired conjugate. The precipitated product was dissolved in $10 \mathrm{mM} \mathrm{NaCl}$ and dialyzed against deionized water to remove water soluble, low molecular weight impurities and byproducts. This approach was employed because removal of intermediates and byproducts by chromatography and extraction proved challenging and resulted in significant loss of product. The isolated material was analyzed by MALDI-TOF mass spectrometry (Figure 2), which indicated the degree of drug loading to be 3:1 LVFX/peptide, with no free peptide detected. Moreover, no intermediate conjugate species were observed. Lower molecular weight regions of spectra from conjugate spectra were compared to the corresponding regions in reference spectra collected for free LVFX and matrix alone (Figure 3) in order to verify the absence of free drug and other low molecular weight impurities.

\section{ANTIBACTERIAL EFFECTIVENESS}

The antibacterial potencies of P4LC, Pep-4, and LVFX, as well as unmodified Pep-4 assayed in combination with free LVFX

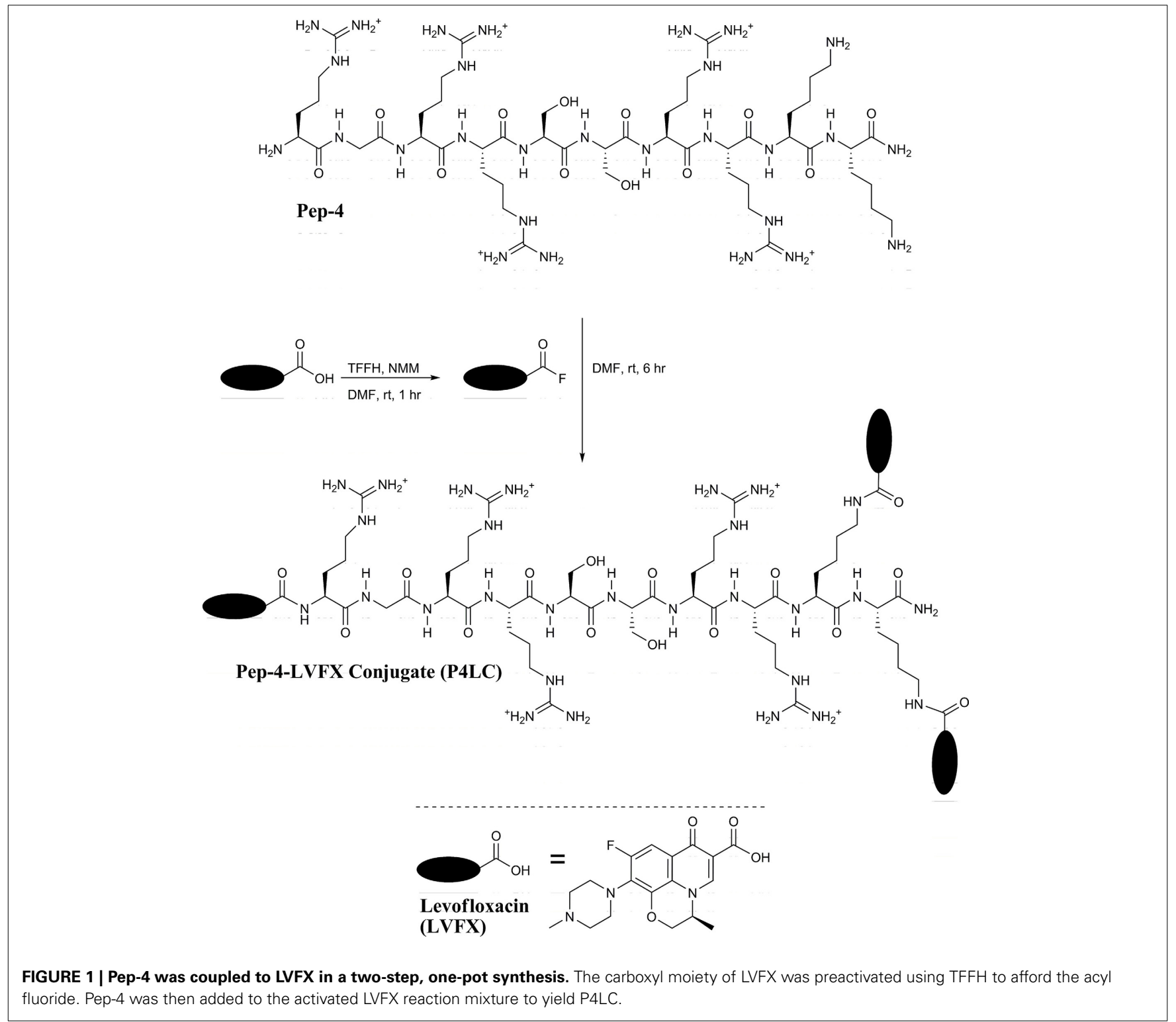




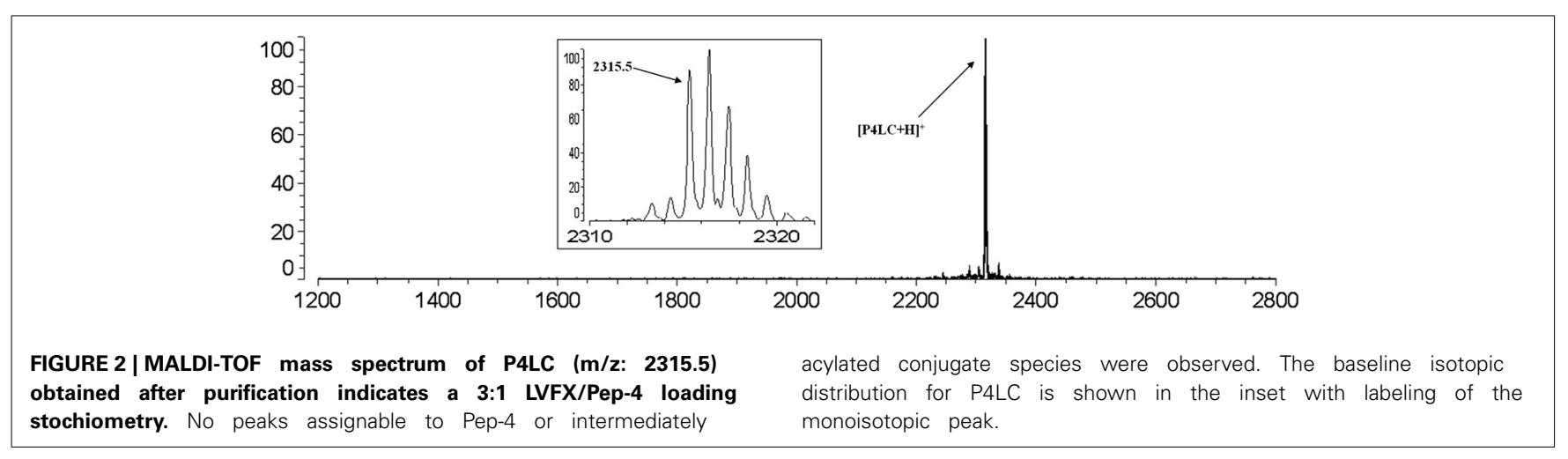

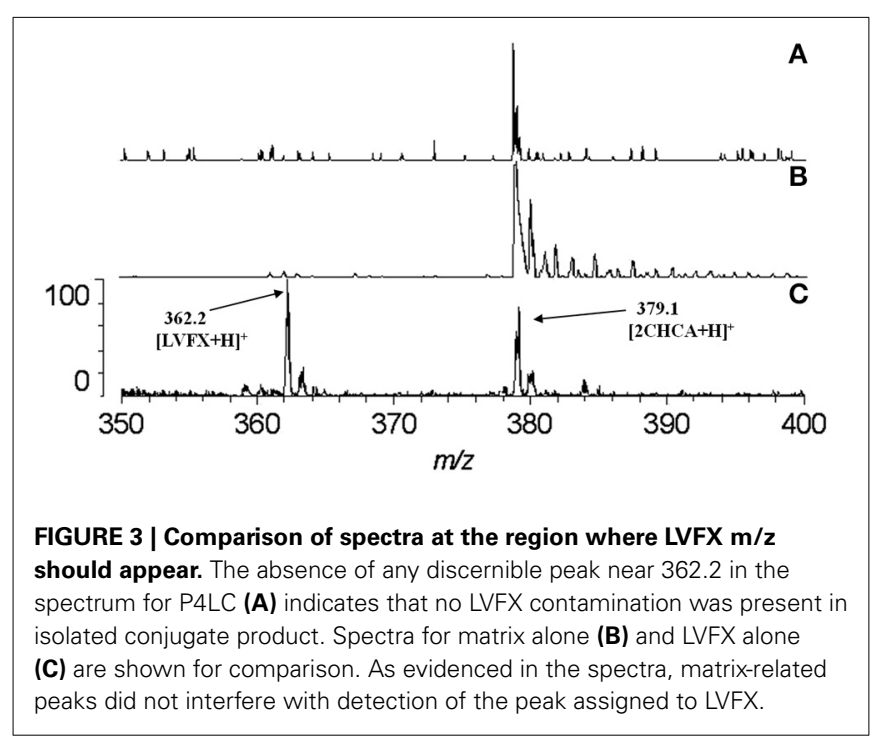

(Pep-4/LVFX), were evaluated against the model gram-negative and gram-positive bacteria E. coli and B. cereus, respectively. Assays were conducted under three different ionic strength $(\mu)$ buffer conditions in order to assess the effect salt concentration had on antibacterial effectiveness. The lowest ionic strength buffer used was $10 \mathrm{mM} \mathrm{NaPO}_{4}, \mathrm{pH} 7.4$, which corresponded to $26 \mathrm{mM}$ total ionic strength. The intermediate ionic strength buffer consisted of $10 \mathrm{mM} \mathrm{NaPO}_{4}$ combined with cation-adjusted PBS in a one to one volume ratio, which afforded a $111 \mathrm{mM}$ ionic strength buffer with a $\mathrm{pH}$ of 7.4. Undiluted cation-adjusted PBS $(\mathrm{pH}=$ 7.4), with an ionic strength of $167 \mathrm{mM}$, was used as the high ionic strength buffer. Bacterial survival results were plotted against the $\log$ of the concentration of conjugate, peptide, or free drug. $\mathrm{EC}_{50}$ values for each assessed compound were calculated by fitting the survival data to equation 3 , which models typical sigmoidal doseresponse behavior using a variable Hill slope. An F test was used to assess statistical significance, with the alpha level set to $0.05 . \mathrm{EC}_{50}$ values and their respective $95 \%$ confidence intervals are shown in Table 1, and generated survival curves are shown in Figure 4.

In low ionic strength conditions $(\mu=26 \mathrm{mM})$, P4LC demonstrated similar antibacterial activity to Pep-4 against both bacteria. Against E. coli, the conjugate demonstrated an $\mathrm{EC}_{50}$ of $0.0167 \mu \mathrm{M}$, which was not found to be significantly different than that of the free peptide, which displayed an $\mathrm{EC}_{50}$ value of $0.0168 \mu \mathrm{M}(p=0.91)$. Against B. cereus, P4LC demonstrated an $\mathrm{EC}_{50}$ value of $0.0218 \mu \mathrm{M}$, while Pep-4 displayed an $\mathrm{EC}_{50}$ of $0.0271 \mu \mathrm{M}$, values which were also determined not to be significantly different $(p=0.21)$. The combination of free LVFX and Pep-4 (Pep-4/LVFX) demonstrated an $\mathrm{EC}_{50}$ of $0.00375 \mu \mathrm{M}$ against $E$. coli, while that of free LVFX was $0.00281 \mu \mathrm{M}$, values which were not significantly different from each other $(p=0.20)$. Against B. cereus, Pep-4/LVFX had an $\mathrm{EC}_{50}$ of $0.112 \mu \mathrm{M}$ and free LVFX an $\mathrm{EC}_{50}$ of $0.212 \mu \mathrm{M}$, values which were approximately five-fold and ten-fold greater, respectively, than those determined for P4LC and Pep-4. The $\mathrm{EC}_{50}$ value of Pep-4/LVFX was not significantly different than that of free LVFX alone $(p=0.36)$ against B. cereus.

P4LC demonstrated $\mathrm{EC}_{50}$ values of $1.71 \mu \mathrm{M}$ and $2.17 \mu \mathrm{M}$ against $E$. coli and B. cereus, respectively, in intermediate ionic strength conditions $(\mu=111 \mathrm{mM})$. These values are approximately 17 -fold and 82 -fold lower than those of Pep-4, $28.3 \mu \mathrm{M}$ (E. coli) and $178 \mu \mathrm{M}$ (B. cereus), under the same conditions. Against $B$. cereus, Pep-4 displayed antibacterial activity only at high peptide concentrations, killing a maximum of $69 \%$ of bacteria at the highest assessed peptide concentration $(491 \mu \mathrm{M})$. In order to fit the data to Equation 3 and estimate the potency of Pep- 4 , it was necessary to set the lower boundary to $0 \%$, a constraint not typically imposed. Therefore, the $\mathrm{EC}_{50}$ value given for Pep-4 against B. cereus under these conditions represents an estimated value. P4LC, LVFX, and Pep-4/LVFX provided sufficient data points in the lower survival ranges to fit the data by setting the lower survival boundary to $\geq 0 \%$. Overall, the potencies of P4LC and Pep-4 decreased significantly compared to their respective performances against both bacteria under low salt conditions. Meanwhile, the potencies of Pep-4/LVFX $(0.00487 \mu \mathrm{M})$ and free $\operatorname{LVFX}(0.00223 \mu \mathrm{M})$ against $E$. coli were not significantly affected by the increased ionic strength. However, in the case of $B$. cereus, the $\mathrm{EC}_{50}$ values for Pep-4/LVFX $(0.941 \mu \mathrm{M})$ and free LVFX $(0.591 \mu \mathrm{M})$ were significantly higher than those observed under low ionic strength conditions. The potencies of Pep-4/LVFX and LVFX were not found to be significantly different from each other for either E. coli $(p=0.071)$ or B. cereus $(p=0.11)$ under these conditions.

Under high ionic strength conditions $(\mu=167 \mathrm{mM})$, the conjugate demonstrated $\mathrm{EC}_{50}$ values of $1.51 \mu \mathrm{M}$ and $40.0 \mu \mathrm{M}$ against E. coli and B. cereus, respectively. By comparison, the $\mathrm{EC}_{50}$ 


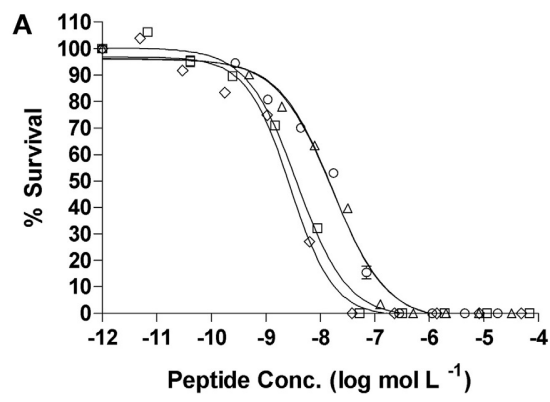

\section{Pep-4}
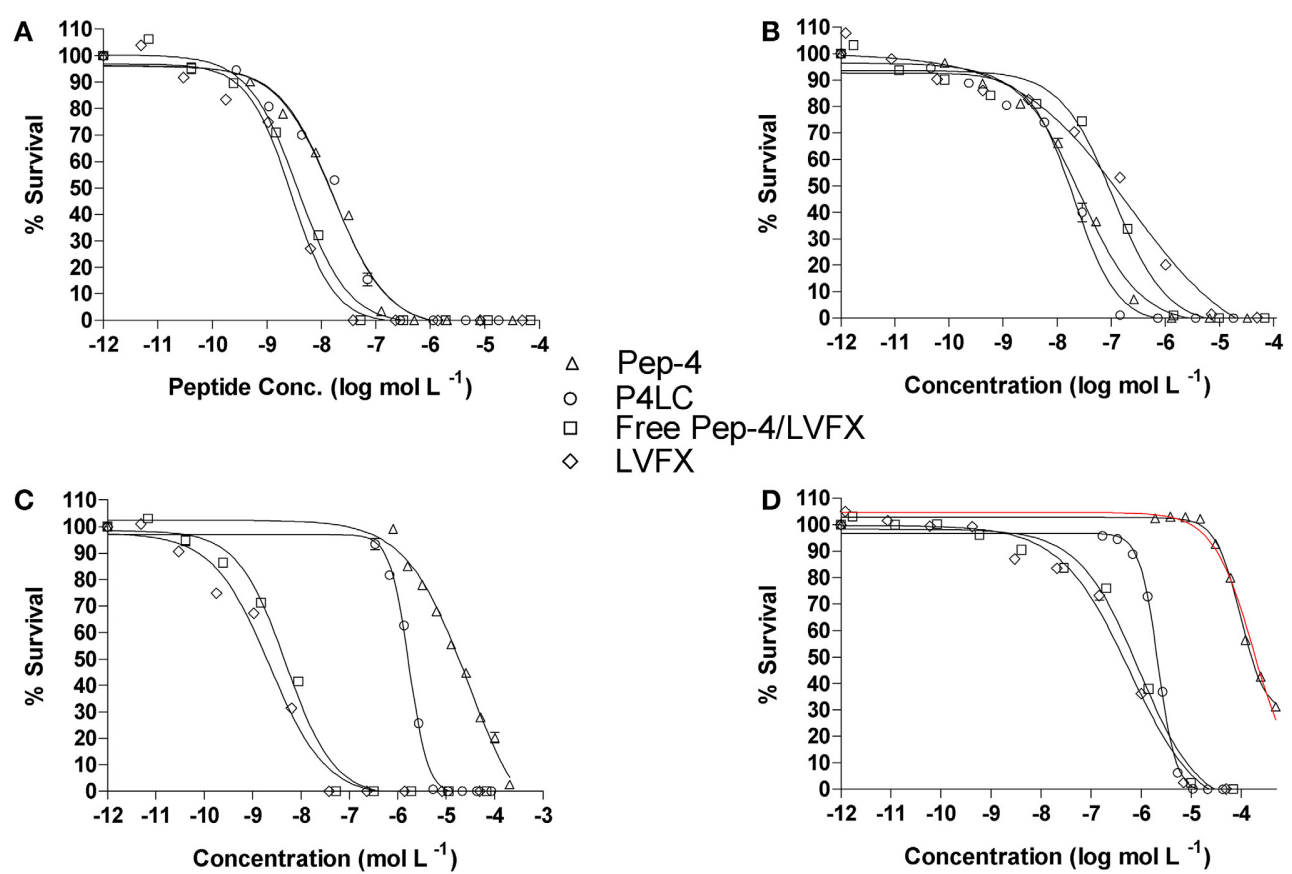

Free Pep-4/LVFX

LVFX
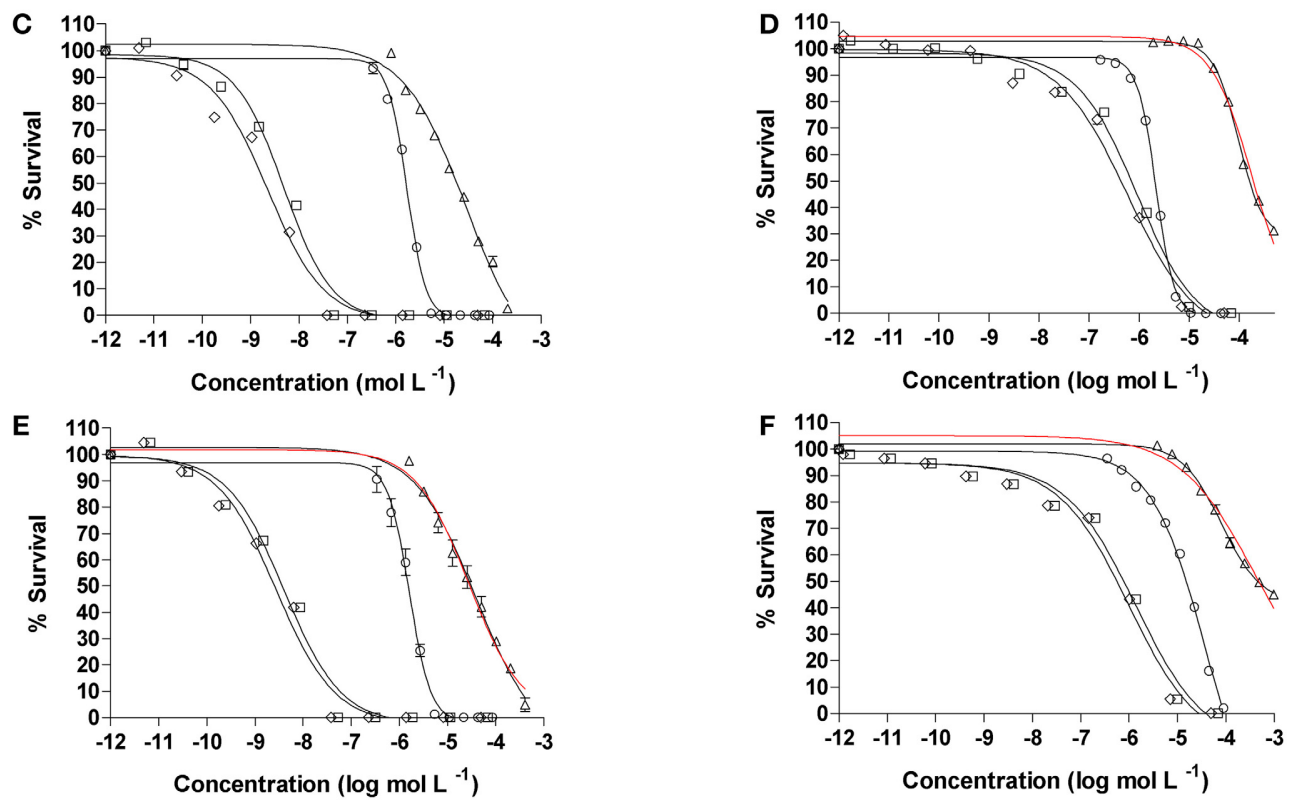

FIGURE 4 | Antibacterial effectiveness of P4LC, Pep-4, Pep-4/LVFX and LVFX against $\boldsymbol{E}$. coli $(\mathbf{A}, \mathbf{C}, \mathrm{E})$ and $\boldsymbol{B}$. cereus $(\mathbf{B}, \mathbf{D}, \mathbf{F})$. The top row $(\mathbf{A}, \mathbf{B})$ were generated for assays performed in low total ionic strength $(26 \mathrm{mM})$, the middle row (C,D) for intermediate total ionic strength $(111 \mathrm{mM})$, and the bottom row (E,F) for high total ionic strength $(167 \mathrm{mM})$ conditions. Data were fit to equation 3, a standard variable slope dose-response equation, in order to obtain $\mathrm{EC}_{50}$ values. Pep-4 failed to achieve sufficient killing (within the tested peptide concentration range) to define the lower survival boundary for fitting to Equation 3 under higher ionic strength conditions (D-F), and it was necessary to set the lower boundary to 0 . Curves based on the data constraints are shown in red. values achieved under high salt conditions with free peptide were $29.4 \mu \mathrm{M}$ against $E$. coli and $404 \mu \mathrm{M}$ against $B$. cereus. Thus, as was the case in the intermediate ionic strength environment, P4LC proved significantly more effective than Pep-4 (approximately 20-fold and 10-fold more potent against E. coli and B. cereus, respectively). Pep-4 failed to exert full killing activity under high ionic strengths within the range of concentrations evaluated, killing a maximum of $90 \%$ of $E$. coli (highest tested peptide concentration was $410 \mu \mathrm{M}$ ) and $56 \%$ of B cereus (highest peptide concentration tested was $983 \mu \mathrm{M})$. Therefore, it was necessary to set the lower survival boundary to $0 \%$ against both bacteria for Pep-4. The conjugate's $\mathrm{EC}_{50}$ against E. coli did not change significantly as a result of the ionic strength increase from 111 to $167 \mathrm{mM}$, while its effectiveness against $B$. cereus decreased by approximately an order of magnitude as a result of the change in environment. This trend was similar to that observed with Pep-4, where the peptide exhibited a substantial increase in its $\mathrm{EC}_{50}$ value against $B$. cereus, though not against $E$. coli, as a result of the assay ionic strength increase from 111 to $167 \mathrm{mM}$. Under high ionic strength conditions, the Pep-4/LVFX combination demonstrated an $\mathrm{EC}_{50}$ of $0.00404 \mu \mathrm{M}$ against $E$. coli and free LVFX exhibited an $\mathrm{EC}_{50}$ of $0.00277 \mu \mathrm{M}$. The values were not found to be significantly different from each other $(p=0.51)$. Moreover, their high salt $\mathrm{EC}_{50}$ values were not significantly different from the $\mathrm{EC}_{50}$ values that they demonstrated under intermediate ionic strength conditions. Meanwhile, Pep-4/LVFX exhibited an $\mathrm{EC}_{50}$ of $1.37 \mu \mathrm{M}$ against $B$. cereus, and free LVFX showed an $\mathrm{EC}_{50}$ of $0.981 \mu \mathrm{M}$, values that were determined to not be significantly different from each other or the corresponding values observed under intermediate ionic strength conditions.

\section{MEMBRANE DISRUPTION}

CAMPs have been shown to directly perturb bacterial membrane integrity, with the degree of inflicted disruption varying 
depending on both the peptide and the bacteria being targeted. CAMP-induced membrane disruption can range from the formation of minor transient gaps that result in depolarization of the membrane to the formation of larger perturbations and pores (Kaplan et al., 2011). The degree of disruption in bacterial cell membranes can be probed using fluorometric reporter molecules such as DiSC(3)5 (for depolarization) (Síp et al., 1990; Zhu and Shin, 2009) and SYTOX Green (for more substantial membrane disruption) (Luque-Ortega et al., 2008).

The ability of P4LC, Pep-4, LVFX, and Pep-4/LVFX to depolarize bacterial membranes was examined using the carbocyanin dye DiSC(3)5. When exposed to live cells, DiSC(3)5 concentrates in hyperpolarized membranes (Síp et al., 1990; Kaplan et al., 2011), which results in quenching of its fluorescence $\left(622 / 670 \mathrm{~nm}_{\mathrm{em}}\right)$. Dissipation of membrane potential gradients resulting from even minor transient disruptions in lipid bilayer integrity inflicted by antibacterial agents such as CAMPs results in the release of trapped DiSC(3)5, which can be detected by monitoring DiSC(3)5 fluorescence (Rathinakumar et al., 2009; Zhu and Shin, 2009). In this study, fluorescence induction curves were generated for conjugate, peptide, or drug in the presence of E. coli and B. cereus cells that had been charged with DiSC(3)5. The data sets for P4LC, Pep-4, LVFX, and Pep-4/LVFX were compared to that obtained for melittin (Lee et al., 2013b), a known pore-forming CAMP that was used as a positive control to establish maximal depolarization. Data for DiSC(3) 5 release was fit to a polynomial regression model (equation 4, see Materials and Methods) and these data were then subjected to an F test, with the alpha level set to 0.01 , in order to allow comparison of curves and establish statistical significance of any observed similarities or differences. Fitted curves are shown in Figures 5A,B.

Addition of P4LC to wells containing E. coli and B. cereus led to a rapid increase in fluorescence in both cases. Compared to the results obtained for melittin, P4LC was able to cause 53.6 and $33.5 \%$ mean maximal fluorescence against E. coli and B. cereus, respectively. In contrast, Pep-4 caused $26.6 \%$ maximal fluorescence against E. coli and 7\% against B. cereus. Similarly, Pep-4/LVFX induced 25\% maximal fluorescence against $E$. coli and $7.4 \%$ against $B$. cereus. Finally, free LVFX was only able to cause $8.4 \%$ and $2.5 \%$ of maximal fluorescence against $E$. coli and $B$. cereus, respectively. The best-fit curves generated for P4LC and free LVFX were found to be significantly different from those of Pep-4 and Pep-4/LVFX, as well as from each other. Meanwhile, the curves generated for Pep- 4 and for Pep-4/LVFX were found to not be significantly different from each other $(p=0.32$ for E. coli; $p=0.071$ for B. cereus).

The membrane impermeable reporter SYTOX green was used as a probe to gain further insight into the effects of P4LC, Pep-4, LVFX, and Pep-4/LVFX on E. coli and B. cereus cell membrane integrity. SYTOX Green has been shown to bind DNA, which results in a $>500$-fold increase in fluorescence intensity. The DNA found in intact bacteria is inaccessible to SYTOX Green binding,
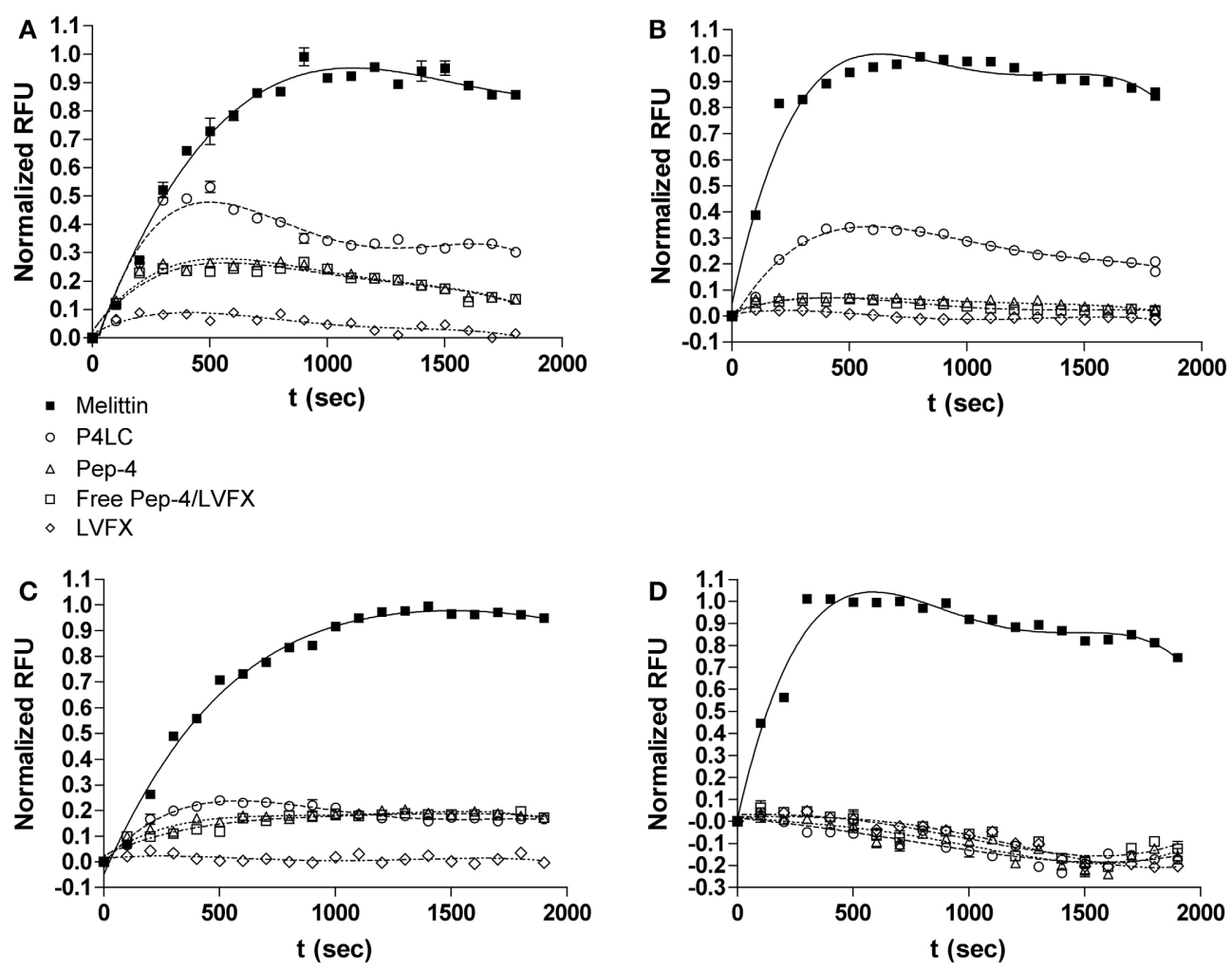

FIGURE 5 | Depolarization (top row) and perturbation (bottom row) of $E$. coli membranes $(A, C)$ and $B$. cereus membranes (B,D) induced by P4LC, Pep-4, Pep-4/LVFX, LVFX and melittin.

Fluorescence values are presented as a percentage of the maximal fluorescence signal intensities observed for the pore-forming CAMP, melittin. 
with fluorescence occurring only after the integrity of the bacterial membrane has been sufficiently compromised (Roth et al., 1997). Whereas DiSC(3)5 requires only minor and transient disruption in membrane integrity for its release from membranes, SYTOX Green requires more substantial perturbation to enter the bacterial cytoplasm and bind DNA. Accordingly, incubation of bacteria with CAMPs that perturb membrane integrity sufficiently for SYTOX green to enter the cytoplasm results in an increase in fluorescence (Lee et al., 2013b). As with the membrane depolarization studies described above, fluorescence curves were generated for P4LC, Pep-4, LVFX, and Pep-4/LVFX, and the data sets compared to those generated for melittin, which was used as the positive reference to establish maximal SYTOX Green fluorescence. Fluorescence induction curves were fit to equation 4 for statistical assessment (Figures 5C,D).

Addition of P4LC to wells containing E. coli led to a moderate increase in fluorescence; however, no noticeable increase in fluorescence was noted for B. cereus. In the case of E. coli, incubation with P4LC resulted in 21.4\% mean maximal fluorescence relative to the results obtained for melittin. Pep-4 afforded 19.1\% maximal fluorescence against E. coli and, similar to P4LC, yielded no noticeable fluorescence increase with $B$. cereus. The best-fit curve for P4LC when incubated with $E$. coli was found to be significantly different than that of Pep-4 $(p<0.0001)$, while the curves for Pep- 4 and P4LC against $B$. cereus were not found to be significantly different $(p=0.44)$. Similar to P4LC and Pep4, Pep-4/LVFX provided approximately one fifth of the maximal fluorescence increase when incubated with $E$. coli and no noticeable increase with $B$. cereus. The best-fit curves for Pep-4/LVFX were found to be significantly different than those of P4LC ( $p<$ 0.0001 ) for both bacteria. However, the best-fit curves for Pep4/LVFX were determined to not be significantly different from those of Pep-4 ( $p=0.012$ for E. coli; $p=0.062$ for B. cereus). No increase in fluorescence was noted when either bacterium was incubated with LVFX.

\section{DISTRIBUTION COEFFICIENT}

Hydrophobic moment is known to be a crucial factor influencing CAMP membrane dynamics and overall antibacterial activity (Liu and Deber, 1998; Stark et al., 2002; Chen et al., 2007; Yin et al., 2012; Lee et al., 2013a). In order to gain insight into the relative hydrophobicities of P4LC, Pep-4, and LVFX, their partitioning between aqueous $10 \mathrm{mM} \mathrm{NaPO}_{4}(\mathrm{pH} 7.4)$ and 1octanol, a non-polar solvent that is immiscible with water, was assessed. The concentration ratios of each compound between the two liquid phases were used to establish distribution coefficients $\left(D_{7.4}\right)$. Indolicidin and melittin were used as reference peptides in these studies. Indolicidin is a short tryptophan and prolinerich CAMP with a high overall hydrophobicity (Podorieszach and Huttunen-Hennelly, 2010), while melittin is a well-studied peptide with an intermediately hydrophobic sequence ( $\mathrm{Li}$ et al., 2013). $\log _{7.4}$ values for Pep-4, P4LC, LVFX, melittin, and indolicidin are shown in Figure 6. Based on the results of these partitioning studies, Pep- 4 was found to be the least hydrophobic of the CAMPs tested, demonstrating a $\log \mathrm{D}_{7.4}$ of -2.57 . By comparison, the $\log \mathrm{D}_{7.4}$ of $\mathrm{P} 4 \mathrm{LC}$ was found to be $-1.65\left(\mathrm{D}_{7.4}=\right.$ 0.0210 ), approximately an order of magnitude greater than that of

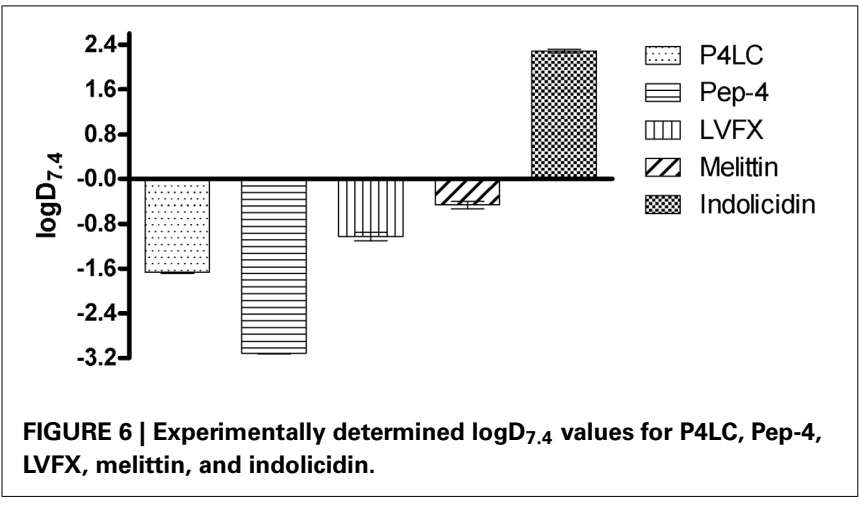

Pep-4. Meanwhile, LVFX demonstrated a $\log \mathrm{D}_{7.4}$ value of -1.05 $\left(D_{7.4}=0.094\right)$, which was about 4.5 -fold greater than P4LC in terms of $\mathrm{D}_{7.4}$. The reference peptide indolicidin was found to have a $\log \mathrm{D}_{7.4}$ value of 2.30 , which was substantially higher than that observed for any other compound tested. The $\log \mathrm{D}_{7.4}$ value for melittin, which was predicted to exhibit intermediate hydrophobicity, was determined to be -0.46 , approximately an order of magnitude greater than that of the conjugate.

\section{DISCUSSION}

These studies have focused on the antibacterial performance of a peptide conjugate comprised of the fluoroquinolone LVFX covalently affixed to Pep-4, a ten-residue CAMP based on the c-terminal sequence of hBD-3. The conjugate, P4LC, was synthesized via acylation of primary amino groups in Pep-4 using the carboxyl moiety of LVFX. Our findings reveal that attachment of LVFX to Pep-4 yields a conjugate with significantly enhanced potency relative to the scaffold peptide in physiologically relevant ionic strength conditions. The results observed for unmodified Pep-4 coadministered with free LVFX suggests that the conjugate's antibacterial potency is not due to extracellular release of free drug.

The antibacterial effectiveness of P4LC, Pep-4, LVFX, and free peptide in combination with free drug (Pep-4/LVFX) were assessed against the model gram-negative and gram-positive bacteria, E. coli and B. cereus, respectively. Assays were conducted in various ionic strength environments, including physiologically relevant conditions, in order to evaluate the effect that salt concentration had on their antibacterial potencies. While P4LC and Pep-4 did not demonstrate significantly different $\mathrm{EC}_{50}$ values against either bacterium in the lowest ionic strength conditions tested ( $\mu=26 \mathrm{mM}$ ), the conjugate was found to be substantially more effective than the free peptide at higher ionic strengths. At an ionic strength of $111 \mathrm{mM}, \mathrm{P} 4 \mathrm{LC}$ was found to be 17 -fold more effective than Pep-4 against E. coli and 82-fold more effective against $B$. cereus. In the highest salt concentrations tested $(\mu=167 \mathrm{mM})$, P4LC was 20 -fold more effective than free peptide against $E$. coli and 10 -fold more effective against $B$. cereus. Meanwhile, $\mathrm{EC}_{50}$ values determined for Pep-4/LVFX were significantly lower than those of the conjugate in all conditions, with the exception being the lowest ionic strength environment, where the conjugate was significantly more effective against $B$. cereus. These findings suggest that the enhanced activity of the conjugate 
relative to the free peptide is likely not due to the activity of extracellular LVFX release. Our findings also suggest that there was no synergistic enhancement of LVFX activity conferred by coadministration of unmodified Pep-4 with free LVFX, as EC50 values for Pep-4/LVFX were in most cases not found to be significantly lower than those of LVFX.

In order to gain insights into the antibacterial mechanisms of P4LC and Pep-4, experiments were performed to investigate their interactions with bacterial membranes. The fluorescent potentiometric probe DiSC(3)5 was used to assess the extent to which P4LC, Pep-4, LVFX, and Pep-4/LVFX were able to induce bacterial membrane depolarization. Compared to melittin, a known pore-forming CAMP, P4LC induced moderate levels of depolarization against both E. coli and B. cereus. Whereas, the depolarization affected by Pep- 4 in E. coli and B. cereus was found be approximately a half and a third, respectively, of that caused by the conjugate. Similar to Pep-4, the Pep-4/LVFX combination afforded minimal depolarization, with fluorescence curves found not to be significantly different than those achieved using the free peptide alone. Meanwhile, LVFX induced almost no detectable depolarization. These results suggest that the covalently bound fluoroquinolone enhanced the peptide's ability to depolarize the membranes of both $E$. coli and $B$. cereus relative to the free peptide.

The membrane impermeable DNA-binding dye SYTOX Green was used to further probe the interactions of P4LC and Pep-4 with bacterial membranes. In the case of E. coli, P4LC and Pep4 were observed to induce a moderate increase in fluorescence, equivalent to approximately one fifth of that observed for the positive reference melittin. Yet, the conjugate induced a more rapid increase in fluorescence than did the free peptide, a difference that was verified through statistical analysis of regression curves fit to the observed fluorescence kinetics data sets. In the case of $B$. cereus, almost no detectable fluorescence increase was observed for either P4LC or Pep-4. Meanwhile, the data sets acquired for Pep-4/LVFX against both bacteria more closely resembled those of Pep-4 than those of P4LC, an observation that was statistically verified. Treatment with free LVFX was not found to produce an increase in fluorescence against either bacterium. Taken together, these results suggest that P4LC and Pep- 4 both induce a moderate degree of membrane perturbation against $E$. coli, but little, if any, perturbation of $B$. cereus membranes. However, this data also suggests that differences may exist in the membrane disruption mechanisms employed by P4LC and Pep-4 against E. coli.

It has been shown that alteration of peptide hydrophobicity can influence CAMP interaction with membranes (Dathe and Wieprecht, 1999; Podorieszach and Huttunen-Hennelly, 2010; Lee et al., 2013a). Introduction of the moderately lipophilic LVFX would be expected to effectively increase the hydrophobic character of the conjugate relative to the unmodified parent peptide. Using a biphasic 1-octanol/phosphate partitioning system, we found that the conjugate was approximately one order of magnitude more hydrophobic than Pep- 4 based on their respective dissociation constants, $\mathrm{D}_{7.4}$ (Pep-4 $\log \mathrm{D}_{7.4}=-2.57$ vs. P4LC $\log \mathrm{D}_{7.4}=-1.65$ ). This finding was consistent with the observation that the hydrophobicity of the free drug was approximately one and a half orders of magnitude greater than that of free Pep-4 (LVFX $\left.\log \mathrm{D}_{7.4}=-1.05\right)$. The $\log \mathrm{D}_{7.4}$ determined for LVFX that is reported here is in agreement with previously reported values (Brillault et al., 2010; Lemaire et al., 2011). Interestingly, it has been shown previously that increasing the hydrophobicity of ten-residue peptides with similar sequences to Pep-4 resulted in enhanced membrane interactions and reduced sensitivity to environmental salt concentration (Bai et al., 2009). The enhanced hydrophobicity conferred by the attached LVFX groups noted here is likely a factor contributing to the more substantial membrane interactions and increased salt resistance observed for the conjugate relative to the free peptide.

\section{CONCLUSION}

In an effort to explore design parameters for engineering CAMP conjugates with enhanced properties, a novel antimicrobial peptide conjugate, P4LC, was generated by attaching multiple units of the fluoroquinolone antibiotic LVFX to Pep-4, a ten residue CAMP that presents multiple primary amino groups suitable for drug attachment via acylation. Our studies revealed that while P4LC displayed similar antibacterial effectiveness as the unmodified parent peptide Pep-4 under low salt conditions, it was substantially more potent under physiologically relevant high salt conditions. This finding is significant because most CAMPs have historically been found to lose antibacterial effectiveness in physiological ionic strength environments, a fact which has presented a challenge to the development of these peptides for therapeutic applications. Our studies also suggest that the conjugate's antibacterial potency is not due to extracellular release of free drug, as evidenced by the results observed for unmodified Pep- 4 coadministerd with free LVFX. Partitioning studies revealed that P4LC was more hydrophobic than Pep-4, while depolarization studies indicated that the conjugate was able to disrupt membrane integrity to a greater degree than the free peptide. We propose that the conjugate's observed increased hydrophobicity plays a role both in its enhanced salt resistance and ability to depolarize bacterial membranes. However, the influence that the LVFX groups have on the performance of the conjugate may not solely be attributable to the increased hydrophobicity. In our prior studies with Pep-4, acetylation of its amino groups was found to decrease the effective positive charge character of the peptide, which resulted in a significant reduction in potency under low salt conditions. In contrast, acylation of Pep-4 with LVFX did not result in a loss of potency under similar conditions. The superior performance of P4LC, relative to acetylated Pep-4, could reflect contributions from multiple factors. Unlike acetyl groups, LVFX contains protonatable nitrogens that could contribute to the overall cationic character of the conjugate. Additionally, the affixed LVFX groups may contribute some aspects of their inherent antimicrobial activity to that of the conjugate. Future efforts will focus on further investigating factors contributing to the antibacterial properties of P4LC and related conjugates. Parameters contributing to more effectively capturing the inherent antibacterial potency of LVFX will be of particular interest. Insights gained from studying the performance and physicochemical properties of P4LC will provide valuable information that can be used in the design of new conjugates incorporating different peptide scaffolds and a 
broader lexicon of auxiliary molecules, including antibiotics or chemotherapeutics.

\section{ACKNOWLEDGMENTS}

This work was supported by funds provided by the College of Science and the Department of Chemistry and Biochemistry at George Mason University. Publication of this article was funded in part by the George Mason University Libraries Open Access Publishing Fund.

\section{REFERENCES}

Arnusch, C. J., Pieters, R. J., and Breukink, E. (2012). Enhanced membrane pore formation through high-affinity targeted antimicrobial peptides. PLoS ONE 7:e39768. doi: 10.1371/journal.pone.0039768

Bai, Y., Liu, S., Jiang, P., Zhou, L., Li, J., Tang, C., et al. (2009). Structuredependent charge density as a determinant of antimicrobialactivity of peptide analogues of defensin. Biochemistry 48, 7229-7239. doi: 10.1021/ bi900670d

Brillault, J., De Castro, W. V., and Couet, W. (2010). Relative contributions of active mediated transport and passive diffusion of fluoroquinolones with various lipophilicities in a Calu-3 lung epithelial cell model. Antimicrob. Agents Chemother. 54, 543-545. doi: 10.1128/AAC.00733-09

Brogden, K. A. (2005). Antimicrobial peptides: pore formers or metabolic inhibitors in bacteria? Nat. Rev. Microbiol. 3, 238-250. doi: 10.1038/nrmicrol098

Chen, Y., Guarnieri, M. T., Vasil, A. I., Vasil, M. L., Mant, C. T., and Hodges, R. S. (2007). Role of peptide hydrophobicity in the mechanism of action of alphahelical antimicrobial peptides. Antimicrob. Agents Chemother. 51, 1398-1406. doi: 10.1128/AAC.00925-06

Cheng, T. J., Weinheimer, S., Tarbet, E. B., Jan, J. T., Cheng, Y. S., Shie, J. J., et al. (2012). Development of oseltamivir phosphonate congeners as anti-influenza agents. J. Med. Chem. 55, 8657-8670. doi: 10.1021/jm3008486

Chu, H. L., Yu, H. Y., Yip, B. S., Chih, Y. H., Liang, C. W., Cheng, H. T., et al. (2013). Boosting salt resistance of short antimicrobial peptides. Antimicrob. Agents Chemother. 57, 4050-4052. doi: 10.1128/AAC.00252-13

Chu-Kung, A. F., Bozzelli, K. N., Lockwood, N. A., Haseman, J. R., Mayo, K. H., and Tirrell, M. V. (2004). Promotion of peptide antimicrobial activity by fatty acid conjugation. Bioconjug. Chem. 15, 530-535. doi: 10.1021/bc0341573

Chyan, W., Zhang, D. Y., Lippard, S. J., and Radford, R. J. (2014). Reaction-based fluorescent sensor for investigating mobile $\mathrm{Zn}^{2+}$ in mitochondria of healthy versus cancerous prostate cells. Proc. Natl. Acad. Sci. U.S.A. 111, 143-148. doi: 10.1073/pnas.1310583110

Dathe, M., and Wieprecht, T. (1999). Structural features of helical antimicrobial peptides: their potential to modulate activity on model membranes and biological cells. Biochim. Biophys. Acta 1462, 71-87. doi: 10.1016/S00052736(99)00201-1

Devocelle, M. (2012). Targeted antimicrobial peptides. Front. Immunol. 3:309. doi: 10.3389/fimmu.2012.00309

Epand, R. M., and Vogel, H. J. (1999). Diversity of antimicrobial peptides and their mechanisms of action. Biochim. Biophys. Acta 1462, 11-28. doi: 10.1016/S00052736(99)00198-4

Gordon, Y. J., Romanowski, E. G., and McDermott, A. M. (2005). A review of antimicrobial peptides and their therapeutic potential as anti-infective drugs. Curr. Eye Res. 30, 505-515. doi: 10.1080/02713680590968637

Hopp, T. P., and Woods, K. R. (1981). Prediction of protein antigenic determinants from amino acid sequences. Proc. Natl. Acad. Sci. U.S.A. 78, 3824-3828. doi: 10.1073/pnas.78.6.3824

Jenssen, H., Hamill, P., and Hancock, R. E. (2006). Peptide antimicrobial agents. Clin. Microbiol. Rev. 19, 491-511. doi: 10.1128/CMR.00056-05

Kaplan, C. W., Sim, J. H., Shah, K. R., Kolesnikova-Kaplan, A., Shi, W., and Eckert, R. (2011). Selective membrane disruption: mode of action of C16G2, a specifically targeted antimicrobial peptide. Antimicrob. Agents Chemother. 55, 3446-3452. doi: 10.1128/AAC.00342-11

Lee, J. K., Park, S. C., Hahm, K. S., and Park, Y. (2013a). Antimicrobial HPA3NT3 peptide analogs: placement of aromatic rings and positive charges are key determinants for cell selectivity and mechanism of action. Biochim. Biophys. Acta 1828, 443-454. doi: 10.1016/j.bbamem.2012.09.005
Lee, M. T., Sun, T. L., Hung, W. C., and Huang, H. W. (2013b). Process of inducing pores in membranes by Melittin. Proc. Natl. Acad. Sci. U.S.A. 110, 14243-14248. doi: 10.1073/pnas.1307010110

Lemaire, S., Tulkens, P. M., and Van Bambeke, F. (2011). Contrasting effects of acidic $\mathrm{pH}$ on the extracellular and intracellular activities of the anti-gram-positive fluoroquinolones moxifloxacin and delafloxacin against Staphylococcus aureus. Antimicrob. Agents Chemother. 55, 649-658. doi: 10.1128/ AAC.01201-10

Lemos, E. G. M., and Carareto-Alves, L. M. (1998). Short communication: resazurin reducing time as an indicator of bradyrhizobium viable cell count. World J. Microbiol. Biotechnol. 14, 139-141. doi: 10.1023/A:10088492 06064

Li, Z., Yuan, P., Xing, M., He, Z., Dong, C., Cao, Y., et al. (2013). Fatty acid conjugation enhances the activities of antimicrobial peptides. Recent Pat. Food Nutr. Agric. 5, 52-56. doi: 10.2174/2212798411305010008

Liu, L. P., and Deber, C. M. (1998). Guidelines for membrane protein engineering derived from de novo designed model peptides. Biopolymers 47, 41-62.

Luque-Ortega, J. R., van't Hof, W., Veerman, E. C., Saugar, J. M., and Rivas, L. (2008). Human antimicrobial peptide histatin 5 is a cell-penetrating peptide targetin mitochondrial ATP synthesis in Leishmania. FASEB J. 22, 1817-1828. doi: 10.1096/fj.07-096081

Mariscal, A., Lopez-Gigosos, R. M., Carnero-Varo, M., and Fernandez-Crehuet, J. (2009). Fluorescent assay based on resazurin for detection of activity of disinfectants against bacterial biofilm. Appl. Microbiol. Biotechnol. 82, 773-783. doi: 10.1007/s00253-009-1879-x

Okuda, D., Yomogida, S., Tamura, H., and Nagaoka, I. (2006). Determination of the antibacterial and lipopolysaccharide-neutralizing regions of guinea pig neutrophil cathelicidin peptide CAP11. Antimicrob. Agents Chemother. 50, 2602-2607. doi: 10.1128/AAC.00331-06

Pal, S., Mitra, K., Azmi, S., Ghosh, J. K., and Chakraborty, T. K. (2011). Towards the synthesis of sugar amino acid containing antimicrobial noncytotoxic CAP conjugates with gold nanoparticles and a mechanistic study of cell disruption. Org. Biomol. Chem. 9, 4806-4810. doi: 10.1039/ clob05338h

Papanastasiou, E. A., Hua, Q., Sandouk, A., Son, U. H., Christenson, A. J., Van Hoek, M. L., et al. (2009). Role of acetylation and charge in antimicrobial peptides based on human beta-defensin-3. APMIS 117, 492-499. doi: 10.1111/j.1600-0463.2009.02460.x

Park, I. Y., Cho, J. H., Kim, K. S., Kim, Y. B., Kim, M. S., and Kim, S. C. (2004). Helix stability confers salt resistance upon helical antimicrobial peptides. J. Biol. Chem. 279, 13896-13901. doi: 10.1074/jbc.M311418200

Podorieszach, A. P., and Huttunen-Hennelly, H. E. (2010). The effects of tryptophan andhydrophobicity on the structure and bioactivity of novel indolicidin derivatives with promising pharmaceutical potential. Org. Biomol. Chem. 8, 1679-1687. doi: 10.1039/b921248e

Radzishevsky, I. S., Rotem, S., Zaknoon, F., Gaidukov, L., Dagan, A., and Mor, A. (2005). Effects of acyl versus aminoacyl conjugation on the properties of antimicrobial peptides. Antimicrob. Agents Chemother. 49, 2412-2420. doi: 10.1128/AAC.49.6.2412-2420.2005

Rathinakumar, R., Walkenhorst, W. F., and Wimley, W. C. (2009). Broad-spectrum antimicrobial peptides by rational combinatorial design and high-throughput screening: the importance of interfacial activity. J. Am. Chem. Soc. 131, 7609-7617. doi: 10.1021/ja8093247

Roth, B. L., Poot, M., Yue, S. T., and Millard, P. J. (1997). Bacterial viability and antibiotic susceptibility testing with SYTOX green nucleic acid stain. Appl. Environ. Microbiol. 63, 2421-2431.

Seo, M. D., Won, H. S., Kim, J. H., Mishig-Ochir, T., and Lee, B. J. (2012). Antimicrobial peptides for therapeutic applications: a review. Molecules 17, 12276-12286. doi: 10.3390/molecules171012276

Shiloh, M. U., Ruan, J., and Nathan, C. (1997). Evaluation of bacterial survival and phagocyte function with a fluorescence-based microplate assay. Infect. Immun. 65, 3193-3198.

Síp, M., Herman, P., Plásek, J., and Hrouda, V. (1990). Transmembrane potential measurement with carbocyanine dye diS-C3-(5): fast fluorescence decay studies. J. Photochem. Photobiol. B Biol. 4, 321-328. doi: 10.1016/1011-1344(90) 85037-W

Stark, M., Liu, L. P., and Deber, C. M. (2002). Cationic hydrophobic peptides with antimicrobial activity. Antimicrob. Agents Chemother. 46, 3585-3590. doi: 10.1128/AAC.46.11.3585-3590.2002 
Wrolstad, R. E., Decker, E. A., Schartz, S. J., and Sporns, P. (2004). Handbook of Food Analytical Chemistry, Water, Proteins, Enzymes, Lipids, and Carbohydrates, $1 s t$ Edn. Hoboken, NJ: Wiley \& Sons, Inc

Yin, L. M., Edwards, M. A., Li, J., Yip, C. M., and Deber, C. M. (2012). Roles of hydrophobicity and charge distribution of cationic antimicrobial peptides in peptide-membrane interactions. J. Biol. Chem. 287, 7738-7745. doi: 10.1074/jbc.M111.303602

Yu, H. Y., Tu, C. H., Yip, B. S., Chen, H. L., Cheng, H. T., Huang, K. C., et al. (2011). Easy strategy to increase salt resistance of antimicrobial peptides. Antimicrob. Agents Chemother. 55, 4918-4921. doi: 10.1128/AAC. 00202-11

Zasloff, M. (2002). Antimicrobial peptides of multicellular organisms. Nature 415, 389-395. doi: 10.1038/415389a

Zhu, W. L., and Shin, S. Y. (2009). Effects of dimerization of the cell-penetrating peptide Tat analog on antimicrobial activity and mechanism of bactericidal action. J. Pept. Sci. 15, 345-352. doi: 10.1002/psc.1120
Conflict of Interest Statement: The authors declare that the research was conducted in the absence of any commercial or financial relationships that could be construed as a potential conflict of interest.

Received: 31 May 2014; accepted: 07 August 2014; published online: 18 September 2014.

Citation: Rodriguez CA, Papanastasiou EA, Juba M and Bishop B (2014) Covalent modification of a ten-residue cationic antimicrobial peptide with levofloxacin. Front. Chem. 2:71. doi: 10.3389/fchem.2014.00071

This article was submitted to Chemical Biology, a section of the journal Frontiers in Chemistry.

Copyright () 2014 Rodriguez, Papanastasiou, Juba and Bishop. This is an openaccess article distributed under the terms of the Creative Commons Attribution License (CC BY). The use, distribution or reproduction in other forums is permitted, provided the original author $(s)$ or licensor are credited and that the original publication in this journal is cited, in accordance with accepted academic practice. No use, distribution or reproduction is permitted which does not comply with these terms. 